\title{
Erratum to: Correlation of Childhood Obesity and Related Insulin Resistance with Leptin and Retinol Binding Protein 4
}

\author{
Vasanthi Thiruvengadam $^{1}$ - Sumanth Amperayani ${ }^{1}$ - R. Prakash Babu ${ }^{2}$. \\ Ramya Uppuluri ${ }^{3}$
}

Published online: 30 July 2015

(C) Dr. K C Chaudhuri Foundation 2015

Erratum to: Indian J Pediatr

DOI 10.1007/s12098-015-1706-6

In the results section, the normal value of RBP4 is mentioned as $<20 \mathrm{mg} / \mathrm{ml}$ instead of $<20 \mathrm{ng} / \mathrm{ml}$.

The online version of the original article can be found at http://dx.doi.org/ 10.1007/s12098-015-1706-6.

\section{Vasanthi Thiruvengadam}

dr_vasanthi@hotmail.com

1 Department of Pediatrics, Kanchi Kamakoti CHILDS Trust Hospital and The CHILDS Trust Medical Research Foundation, Chennai, Tamil Nadu 600034, India

2 Department of Biochemistry, Kanchi Kamakoti CHILDS Trust Hospital and The CHILDS Trust Medical Research Foundation, Chennai, Tamil Nadu, India

3 Department of Pediatrics, Apollo Specialty Hospitals, Chennai, Tamil Nadu, India 